\title{
Metamaterial superstrate microstrip patch antenna for 5G wireless communication based on the theory of characteristic modes
}

\author{
Ehab K. I. Hamad*, Ahmed Abdelaziz ${ }^{* *}$
}

\begin{abstract}
Metamaterials (MTMs) have received considerable attention due to their novel electromagnetic properties. Their applications include enhancing gain and bandwidth in microstrip antennas. In this article, a dual band microstrip antenna design based on characteristic mode analysis (CMA) using MTM superstrate is proposed for 5G wireless communication. The CMA is used for the modelling, analysis and optimization of the proposed antenna to examine the underlying modal behaviour of the MTM unit cell and to guide mode excitation. The antenna structure consists of a microstrip feed line connected to a rectangular patch. Then triangular split ring resonator unit cell is inserted on the ground of a traditional patch antenna that resonates at $15 \mathrm{GHz}$ to produce additional resonance at $10 \mathrm{GHz}$. A planar array of $2 \times 3$ triangle MTM unit cells is used as superstrate to improve the gain and bandwidth at both resonances simultaneously. The optimal distance between MTM superstrate and the antenna patch is determined using the Fabry-Perot cavity theory to maximize power directivity and efficiency of the proposed antenna. The CST microwave studio software is used to model and optimize the proposed antenna. A prototype of the designed antenna that was fabricated showed good agreement between measurement and simulation results.
\end{abstract}

K e y w or d s: $5 \mathrm{G}$ wireless communications, characteristic mode theory, microstrip antennas, metamaterials

\section{Introduction}

The last few years have witnessed a phenomenal growth in the wireless industry, both in terms of mobile technology and its subscribers. Mobile wireless technologies have undergone 4 or 5 generations of technology revolution and evolution, from $0 \mathrm{G}$ to $4 \mathrm{G}$. The cellular concept was introduced in the era of $1 \mathrm{G}$ technology, making large scale mobile wireless communication possible. Digital communication which replaced $2 \mathrm{G}$ analog technology significantly improved wireless communication quality. In addition to voice communication, data communication became a major focus in $3 \mathrm{G}$ technology that paved the way for a converged network catering to both voice and data communication. 4G wireless communication systems have been initiated in some countries and will soon reach many others. Nevertheless, 4G still faces various challenges like spectrum crisis, high energy consumption, poor coverage, bad interconnectivity, poor quality of service (QoS), and flexibility [1]. To address these shortcomings, the world has set its sights on the $5 \mathrm{G}$ wireless system, expected to be deployed by 2020 [2]. Wireless system designers need to adopt a new approach to concept and design to fulfil the needs of this fifth-generation wireless system that promises higher data rate, better reliability, more connectivity, lower latency, and improved security features $[3,4]$.

The patch antenna, a critical component of the modern wireless communication system, has played a vital role in this evolution. Compared with conventional microwave antennas, microstrip patch antennas are small, light in weight, simple to manufacture, low cost, and they integrate easily into mobile radio and wireless communication applications. Their main limitations are lower gain and bandwidth which can be significantly improved by employing several techniques [5], one of which is the use of metamaterials (MTMs).

Metamaterial is synthetic material which does not exist in nature. Its properties are not defined by its material composition but by its structure which can be elliptical, rectangular, triangular, and circular or any other shapes $[6,7]$. Natural materials normally have positive electric permittivity, magnetic permeability and index of refraction. On the other hand, all these parameters are negative in metamaterials, and they are hence termed negative index materials (NIM) or double negative media (DNG), left-handed materials (LHM) or backward wave media. Among the numerous applications of metamaterials are in the manufacture of perfect lenses, wave retarders, absorbers, cloaks and antennas [8].

Studies on antennas have been reported by many researchers who seek to enhance antenna properties such as bandwidth, gain, efficiency and antenna size. In this connection, a rectangular patch antenna associated with left-handed medium was investigated in [9]. The results showed the antenna to be more directive and the gain to be high, although size reduction remained a major chal-

* Electrical Engineering Department, Aswan Faculty of Engineering, Aswan University, Aswan 81542, Egypt, ** Department of Electronics and Communications, Luxor Higher Institute of Engineering \& Technology, Luxor 85834, Egypt, e.hamad@aswu.edu.eg, eng_ahmed@luxorhiet.edu.eg

DOI: $10.2478 /$ jee-2019-0027, Print (till 2015) ISSN 1335-3632, On-line ISSN 1339-309X

(C) This is an open access article licensed under the Creative Commons Attribution-NonCommercial-NoDerivs License (http://creativecommons.org/licenses/by-nc-nd/3.0/) 

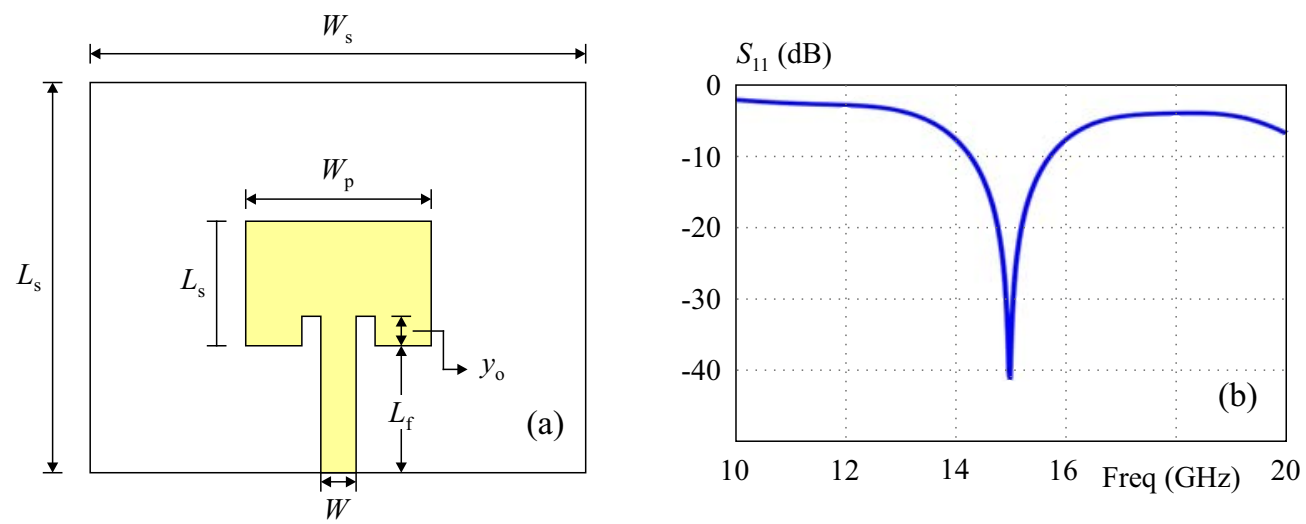

Fig. 1. Traditional microstrip patch antenna: (a) - schematic diagram, (b) - s11 resonates at $15 \mathrm{GHz}$
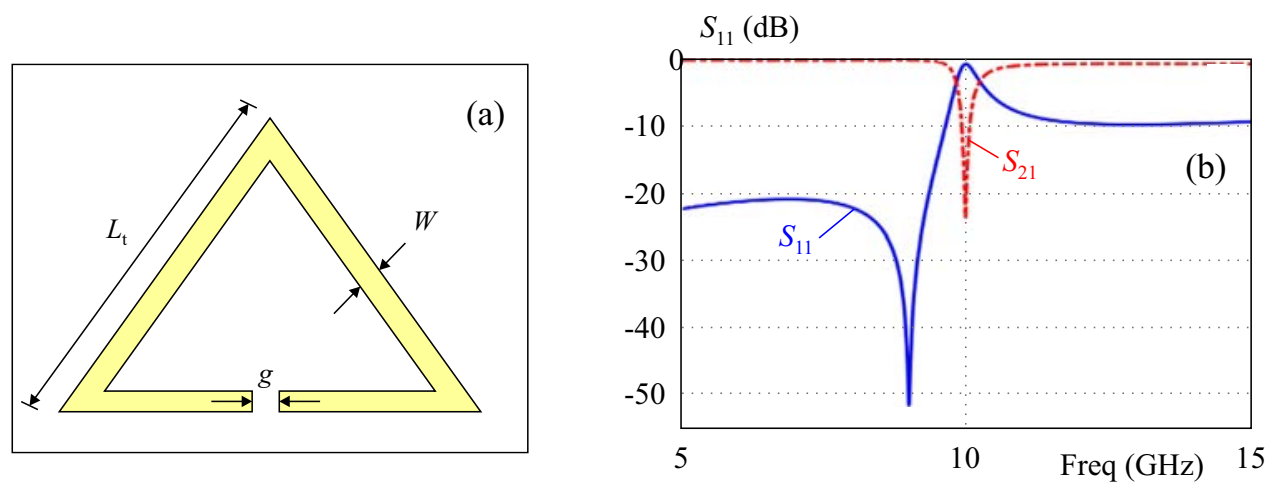

Fig. 2. Equilateral TSRR unit cell operates at $10 \mathrm{GHz}$ (a) - schematic diagram, (b) - S-parameters

lenge. Microstrip antenna gain was considerably enhanced using metamaterial structure in [10], while multiband response was generated using MTM in [11]. Patch antenna bandwidth enhancement using metamaterials was studied in [12]. In [13], a MTM superstrate was placed at a convenient distance above a traditional patch antenna to obtain significant improvement in gain and bandwidth. Other recent research efforts in this area have been reported in [14-17].

Many substrates that are available have dielectric constants that are generally below $10 \mathrm{GHz}$ [18]. Rogers's substrate is the exception in this regard, rendering it our preferred choice for the millimeter wave frequency range, being most suited for UHF (ultra-high frequencies) because of its low dielectric loss and low dispersion [19]. Rogers's substrate also has desirable characteristics of low electric loss and low moisture absorption.

In this paper, a metamaterial-based antenna is proposed for $5 \mathrm{G}$ wireless communication. Its application is examined using the source-free characteristic mode analysis (CMA), which provides useful insights into an understanding of the antennas operating mechanisms. A metamaterial superstrate layer is utilized to accomplish superior gain and bandwidth simultaneously as compared with a traditional microstrip antenna. Simulation and optimization of the proposed antenna structure is performed using a FIM-based CST microwave studio.

\section{Antenna and MTM superstrate design}

In this section, the proposed microstrip patch antenna and MTM superstrate are introduced. The S-parameters of the triangle split ring resonator (TSRR), derived using the effective medium theory, are also discussed here.

\section{1 conventional microstrip patch antenna}

A conventional microstrip patch antenna resonating at $15 \mathrm{GHz}$ is designed as shown in Fig. 1(a). It consists of a rectangular patch on Rogers RT 5880 substrate with its ground plane at the bottom. The substrate is $1.575 \mathrm{~mm}$ thick and has relative permittivity of 2.2 and loss tangent 0.0009 . Inset feeding technique is used to achieve $50 \Omega$ impedance matching. The return loss of the antenna is $-41 \mathrm{~dB}$ at $15 \mathrm{GHz}$ as shown in Fig. 1(b), and the corresponding gain and bandwidth are around $8.07 \mathrm{~dB}$ and $1.3 \mathrm{GHz}$, respectively.

\subsection{TSRR unit cell design and extraction of its effective parameters}

A study on the different shapes of metamaterial such as rectangular, circular, pentagonal, hexagonal and triangular and has been shown that the triangular gives better performance such as return loss and bandwidth as described in [20]. The structure of the TSRR unit cell and its S-parameters are presented in Figs. 2(a) and (b), 

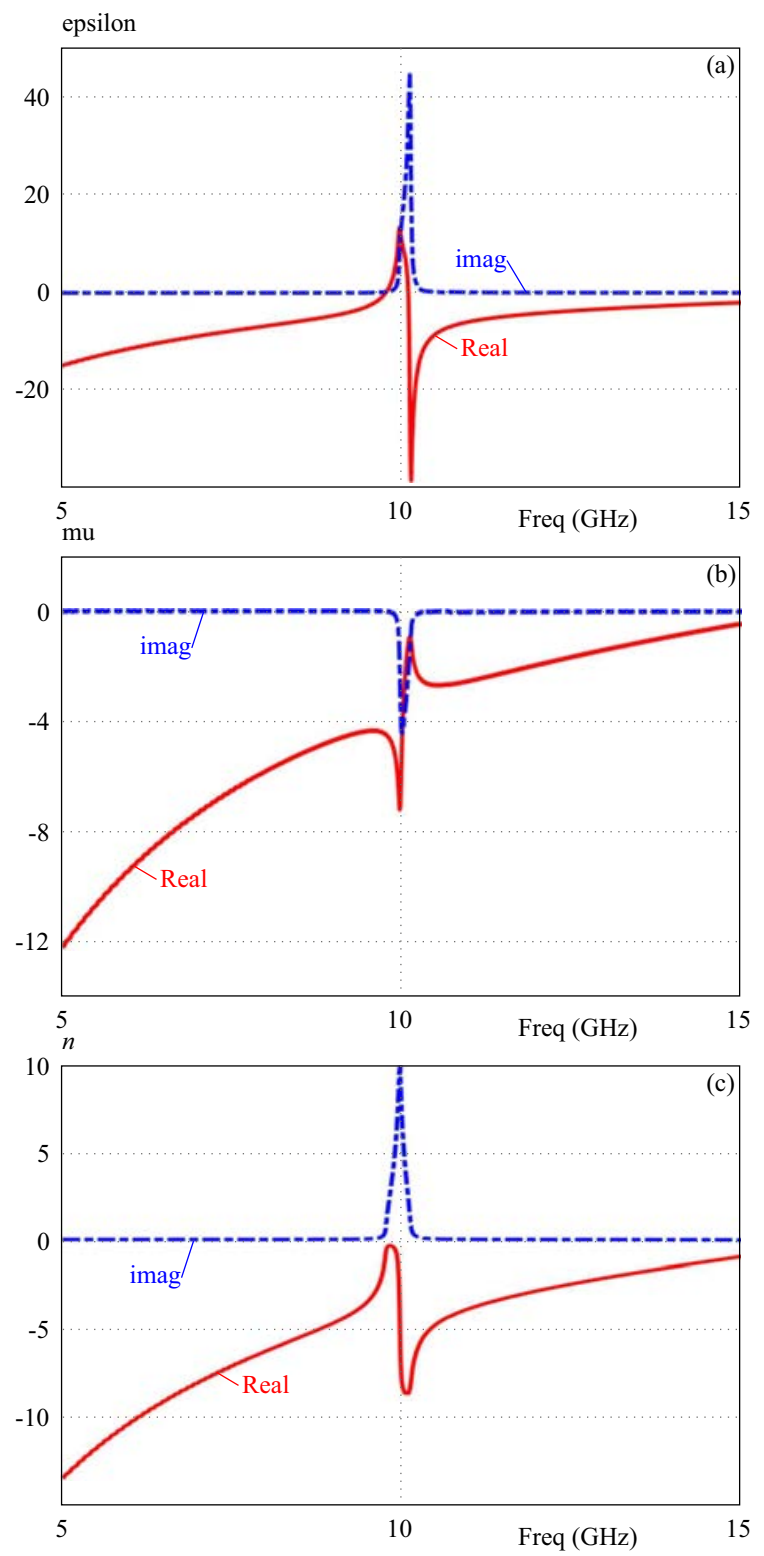

Fig. 3. TSRR MTM unit cell parameters: (a) - effective permittivity, (b) - effective permeability, (c) - refractive index

Table 1. The proposed antenna parameters and values

\begin{tabular}{lcccccc}
\hline Parameter & $W_{s}$ & $L_{s}$ & $W_{p}$ & $L_{p}$ & $Y_{o}$ & $S_{x}$ \\
Value $(\mathrm{mm})$ & 20 & 20 & 7.8 & 6.22 & 1.2 & 1.2 \\
\hline Parameter & $W_{f}$ & $L_{f}$ & $L_{t}$ & $g$ & $W$ & $S_{y}$ \\
Value $(\mathrm{mm})$ & 1.565 & 6.09 & 4.6 & 0.3 & 0.3 & 4.9 \\
\hline
\end{tabular}

respectively. It can be noted that the TSRR unit cell resonates at $10 \mathrm{GHz}$ with a return loss of $-25 \mathrm{~dB}$. The geometrical dimensions of the TSRR unit cell are as follows: length of outer edge of the TSRR $\left(L_{t}\right)=4.6 \mathrm{~mm}$, width of the slot $(W)=0.3 \mathrm{~mm}$, gap width within the side $\operatorname{arm}(g)=0.3 \mathrm{~mm}$. The effective MTM parameters, permittivity $\left(\varepsilon_{\text {reff }}\right)$ and permeability $\left(\mu_{\text {reff }}\right)$ are derived from the S-parameters of the TSRR unit cell based on the algorithm introduced in [21]. The refractive index, relative permittivity and relative permeability of the TSRR unit cell shown in Fig. 3 have negative values at the resonance frequency of $10 \mathrm{GHz}$, as expected. The permittivity of the complementary triangular split ring resonator (CTSRR) unit cell is negative at the operating frequency, conversely with TSRRs of the same dimensions for which negative permeability is expected, this being the main feature of metasurfaces [19].

This CTSRR is employed in the ground plane underneath the patch as depicted in Fig. 4(a). The CTSRRs dimensions and position are optimized to generate additional resonant frequency at $10 \mathrm{GHz}$ without disturb the original resonance. It can be easily noticed that the production of new resonance frequency at $10 \mathrm{GHz}$ with return loss of $-31 \mathrm{~dB}$ and bandwidth of $307 \mathrm{MHz}$ is shown in Fig. 4(b).

To enhance the performance of this antenna for $5 \mathrm{G}$ wireless communication in terms of improved gain, bandwidth, and directivity focusing of the beam, a metamaterial superstrate is introduced as described in the following sub-section.

\section{3 metamaterial superstrate analysis}

Metamaterial (MTM) superstrate can be placed in front of a patch antenna, and due to the negative refractive index property of the MTM, the radiated electromagnetic beam width decreases which results in a highly focused beam, hence the gain, directivity and radiation efficiency can be significantly improved. The geometrical structure of metamaterial superstrate consisting of a $2 \times 3$ array of the TSRR unit cell is depicted in Fig. 5(a). The length and width of the MTM superstrate is taken in such a way that it can effectively cover the patchs broadside radiation. Parametric studies were carried out with different dimensions and different numbers of periodic elements to obtain optimal return loss and optimal radiation parameters. As a result, a 23 periodic structure at $20 \times 15 \mathrm{~mm}^{2}$ dimensions was noted that is the optimum number of array elements, so we used this number of elements in our design after intensive simulations. The perspective and side views of the proposed antenna are illustrated in Figs. 5(b) and (c), respectively. The MTM superstrate is utilized to cover the patch of the traditional antenna without increasing the total area of the suggested antenna, ie the planer areas of loaded and unloaded antennas are almost the same. The overall size of the MTM superstrate layer is $20 \times 15 \mathrm{~mm}^{2}$. It is placed at a distance (d) of $12.5 \mathrm{~mm}$ above the patch of the microstrip antenna. The designated dimensions of the proposed rectangular patch antenna as well as the triangular unit cell are in Tab. 1.

The separation distance between the superstrate layer and the patch is obtained in accordance with the FabryPerot cavity theory, following [11]:

$$
d=\left(1+\frac{\varphi}{\pi}\right) \frac{\lambda}{4}
$$



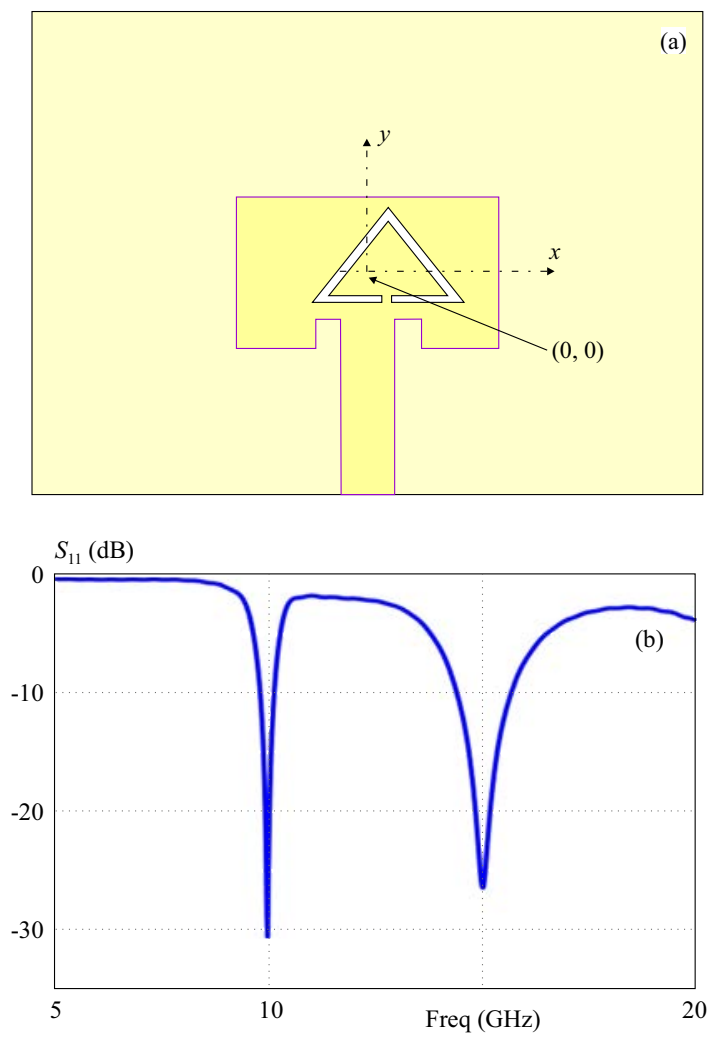

Fig. 4. The microstrip antenna with incorporating CTSRR in the ground plane to operate at dual band of 10 and $15 \mathrm{GHz}$ : (a) schematic diagram, (b) - S11

where $\varphi$ is the reflection angle of the superstrate, and the optimal spacing $d$ is at around the focal point of the design which is $12.5 \mathrm{~mm}$ for $\varphi=120^{\circ}$.

The CST microwave studio simulator that is based on the finite integration technique is used to model this proposed antenna from which measurements are compared to the simulated results to validate the proposed concept. This approach enables considerable improvement in the gain of antenna and in its efficiency as discussed later in this paper.

To understand the operating mechanism of the proposed microstrip patch antenna and TSRR unit cell, the intrinsic characteristic modes (CMs) supported by the TSRR unit cell are investigated according to the theory of characteristic modes (TCM) as detailed in the next section

\section{Characteristic mode analysis}

\section{1 theory of characteristic mode}

The theory of characteristic mode (TCM) was introduced in 1965 [22], and reformulated for computing the CMs for perfectly electric conducting bodies in $1971[23,24]$. TCM became an alternative technique to design microstrip antenna because of the physical insight it brought. It can offer significant data for antenna design, for example expecting resonant frequencies and the right feed position to excite a characteristic mode. The TCM derivation and its application in antenna design are introduced in [25]. Characteristics modes (CM) can be obtained as the eigenfunctions of the particular weighted eigenvalue equation in the form of $X\left(J_{n}\right)=\lambda_{n} R\left(J_{n}\right)$ where the $\lambda_{n}$ are the eigenvalues, the $J_{n}$ are the eigenfunctions or eigencurrents, $n$ is the mode order and $R$ and $X$ are the real and imaginary parts of the MOM impedance matrix $Z=R+j X$ [26]. The eigenvalue is a very beneficial parameter as it makes available the resonant frequency and radiation information of the CM. In practice, however other ways of representation of the eigenvalue may be prioritize. Another factor called modal significance (MS) is substantially important, which is a parameter used to find the resonant frequency as well as the bandwidth offered by a mode and it is determined as $\mathrm{MS}_{n}=\left|1 /\left(1+j \lambda_{n}\right)\right|$. The same information can be extracted from the characteristic angle $\beta_{n}$ that models the phase angle between a characteristic current $J_{n}$ and the associated characteristic field $E_{n}$. It can be calculated as $\beta_{n}=180^{\circ}-\tan ^{-1}\left(\lambda_{n}\right)$. When the characteristic angle is close to $180^{\circ}$ the mode is considered as a good radiator, while when the characteristic angle is near $90^{\circ}$ or $270^{\circ}$ the mode mainly stores energy. When a CM resonates, it is observed that $\lambda_{n}=0$ while $\mathrm{MS}_{n}=1$ and $\beta_{n}=180^{\circ}$. The TCM states that the current patterns can be expressed as an infinite sum of fundamental current modes that are individually weighted by several factors. It can be expressed as $J=\Sigma \alpha_{n} J_{n}$, where $\alpha_{n}$ is determined by the eigenvalue and the modal-excitation coefficient of the $n^{\text {th }}$ mode.

\subsection{CMA of the proposed antenna elements and TSRR unit cell}

To understand the operational mechanism of the antenna elements and TSRR unit cell, the evolution of modal behavior is investigated. The results are obtained using the CMA tool that is based on the method of moments in the CST microwave studio (Ver. 2018) commercial software. Because of the constraint of the integral equation solver, the conventional antenna elements investigated here are set for perfect electric conductor with a thickness of $0.035 \mathrm{~mm}$, without any substrate or excitation $i e$ no feed port utilized in the antenna element for the CMA.

The expected modal significance $\left(\mathrm{MS}_{n}\right)$ and characteristic angles $\left(\beta_{n}\right)$ of the three most pertinent CMs of the patch antenna are presented in Fig. 6 and Fig. 7, respectively. The patch antennas three most pertinent $\mathrm{CMs}$ operate at $9.95 \mathrm{GHz}, 15 \mathrm{GHz}$ and another frequency is above $20 \mathrm{GHz}$. The modal significance shows that the trace of mode 1 is sharper than that of mode 2 , indicating that mode 1 has narrower bandwidth than mode 2 .

The surface current distributions on the patch element are sketched in Fig. 8, where the black arrows point to the directions of current. Other than were specified, all the modal currents and fields shown in this paper are plotted 

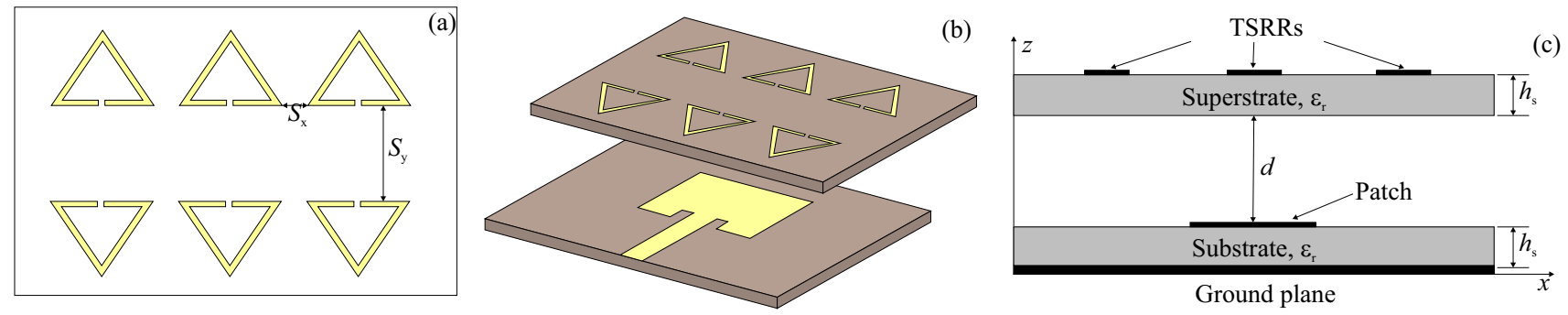

Fig. 5. (a) - geometrical structure of MTM superstrate, (b) - perspective view, (c) - side view of the proposed antenna

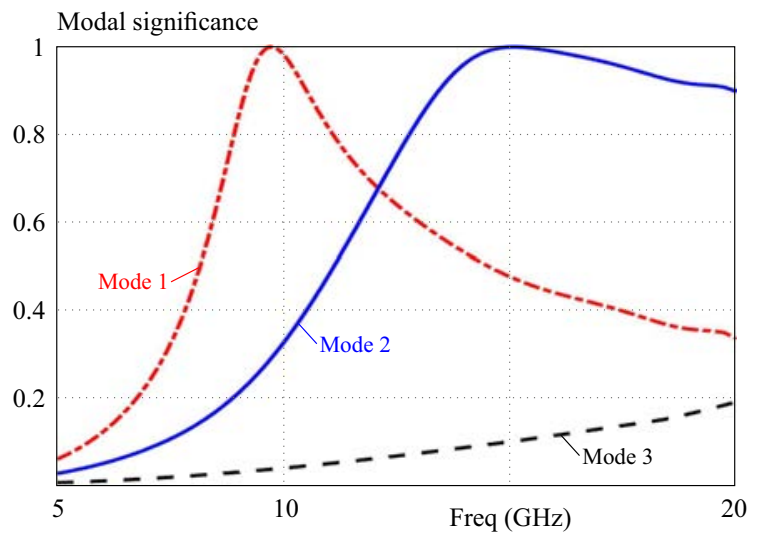

Fig. 6. Expected modal significances of the first three most pertinent cms of the patch antenna
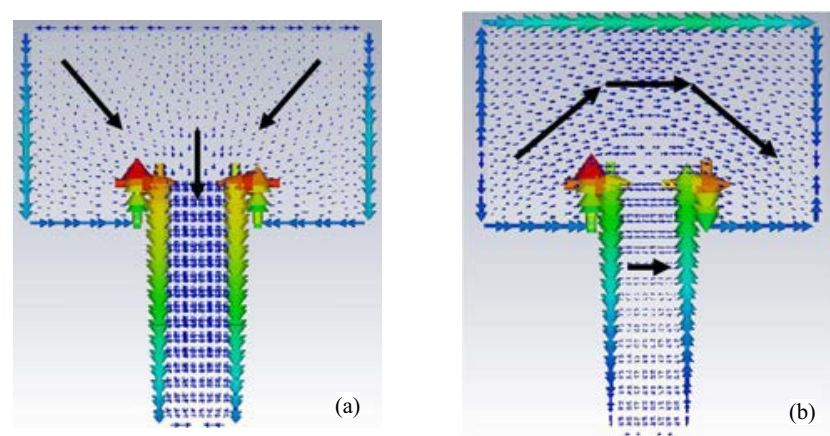

Fig. 8. Expected current distributions of the first two modes of patch element

at $10 \mathrm{GHz}$. The main current of mode 1 is at $10 \mathrm{GHz}$, and that of mode 2 at $15 \mathrm{GHz}$.

Here, we explore the relationship between the TSRR unit cell, patch and the ground plane. The predicted $\mathrm{MS}_{n}$ of the ground plane and TSRR unit cell are depicted in Fig. 9 and Fig. 10, respectively. Fig. 9 demonstrates that the four most pertinent CMs of the ground plane resonate at $7,9.4,10$, and $15 \mathrm{GHz}$. Fig. 10 indicates that of the three most pertinent CMs of the TSRR unit cell, two resonate at 10 and $15.1 \mathrm{GHz}$, while the third has a resonant frequency above $20 \mathrm{GHz}$. The surface current distributions of the TSRR element are demonstrated in Fig. 11.

Figures 12 and 13 present the simulated electric and magnetic fields on the ground plane in the near field at

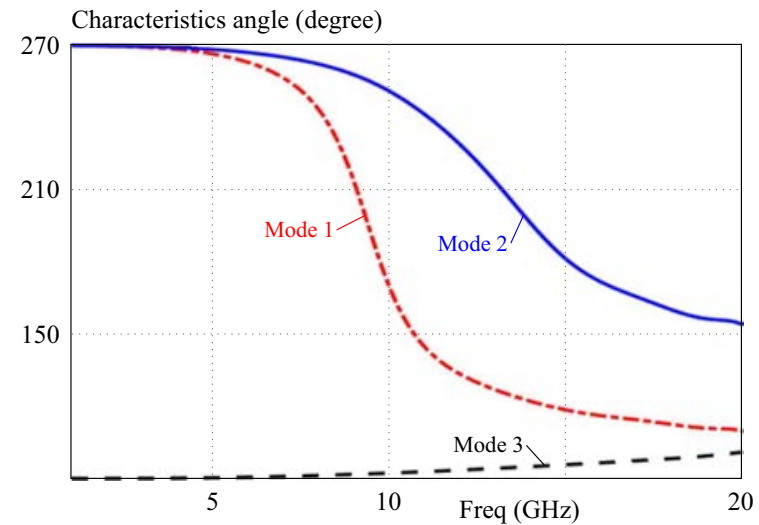

Fig. 7. Expected characteristics angle $\left(\beta_{n}\right)$ of the first three most pertinent $\mathrm{CMs}$ of the patch antenna

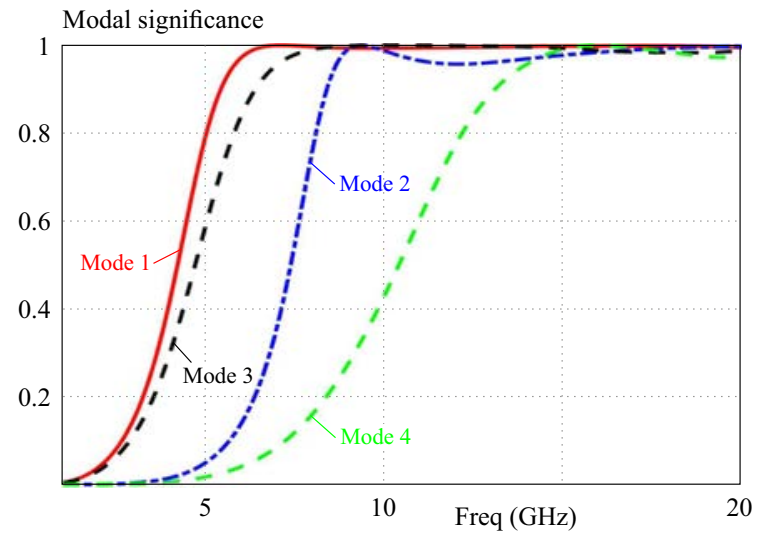

Fig. 9. Predicted modal significances of the first three most relevant $\mathrm{CMs}$ of ground plane

10 and $15 \mathrm{GHz}$. As can be observed from Fig. 12, mode 3 has strong magnetic-field and nulls of electric-field in the center of ground plane. In contrast, in Fig. 13, mode 4 has strong electric-field and nulls of magnetic-field in the center of ground plane. The CTSRR acts as a magnetic source. The term "magnetic source" in this context means that the CTSRR unit cell stores at most magnetic energy in the near field. When a magnetic source is accurately sited at the strong magnetic field point of the CM, it can excite the CM effectively. Hence, CTSRR is able to excite mode 3 of the ground plane effectively. The patch element acts as an electric source. The term "electric source" here means that the patch element stores mainly electric energy in the near field. When an electric source 


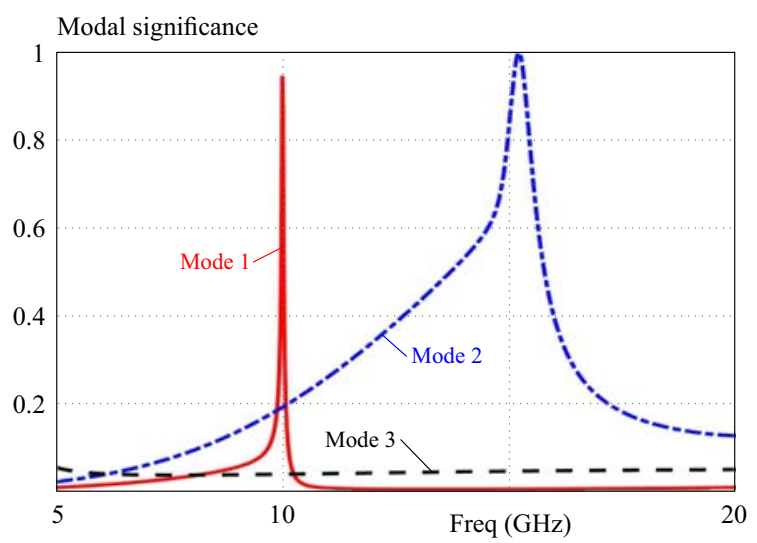

Fig. 10. Predicted modal significances of the first three most relevant CMs of TSRR unit cell

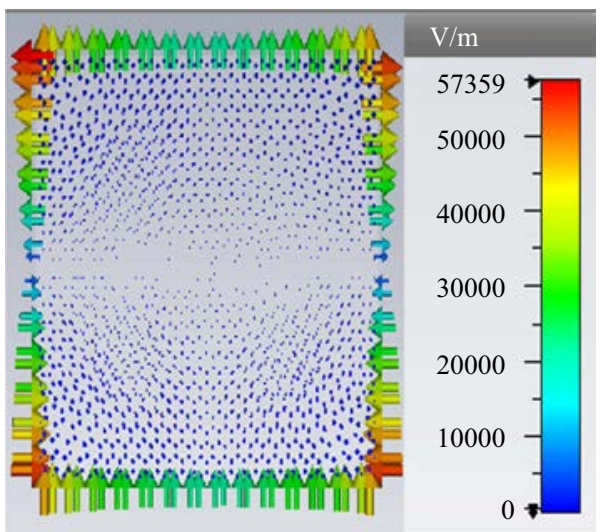

(a)

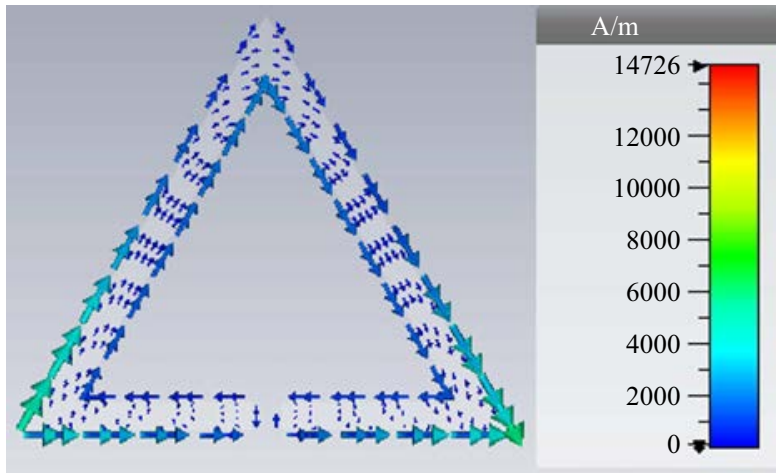

Fig. 11. Predicted current distribution of the first mode

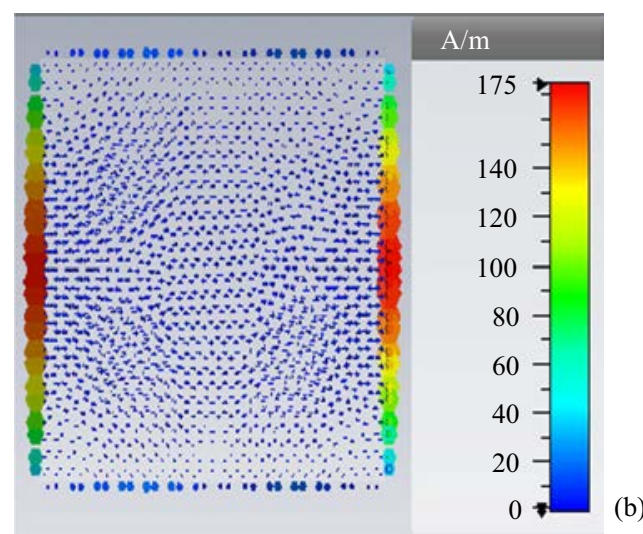

Fig. 12. Electric and magnetic fields on the ground plane in the near field at $10 \mathrm{GHz}$ : (a) - E-field, (b) - H-field

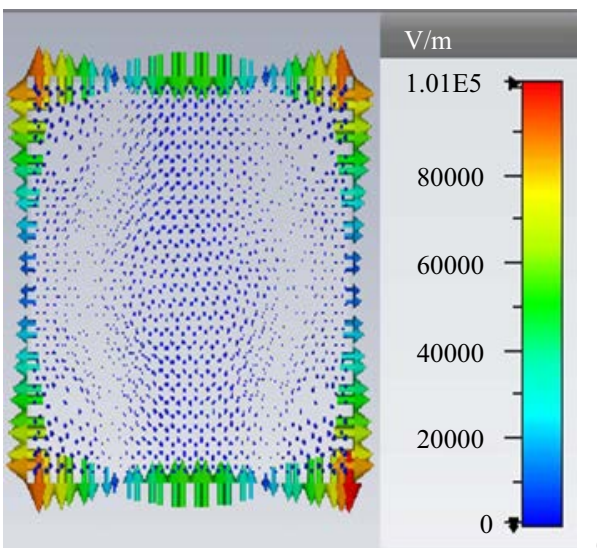

(a)

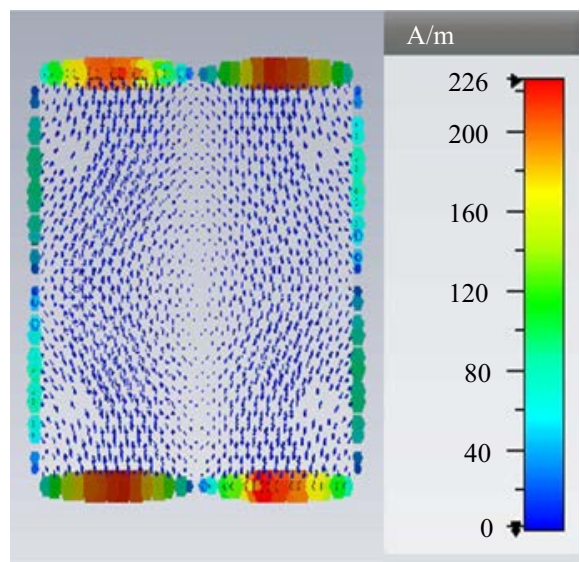

(b)

Fig. 13. Electric and magnetic fields on the ground plane in the near field at $15 \mathrm{GHz}$ : (a) - E-field, (b) - H-field

is accurately sited at the strong electric field point of CM, it can excite the CM effectively. Hence, the patch element is also capable to excite mode 3 of the ground plane efficiently.

\section{Parametric study}

The parametric studies were performed by using the parameter sweep option in CST to obtain maximum en- hancement in gain and bandwidth of the proposed antenna. There is another important parameter that exerts control in gain and bandwidth, namely the separation $(d)$ between the MTM superstrate and the main patch of the antenna. Figs. 14(a) and (b) illustrate the variation of return loss and gain, respectively, at 10 and $15 \mathrm{GHz}$ of the proposed antenna with the amendment in the separation $d$. Maximum gain and bandwidth are obtained for $d=12.5 \mathrm{~mm}$. 

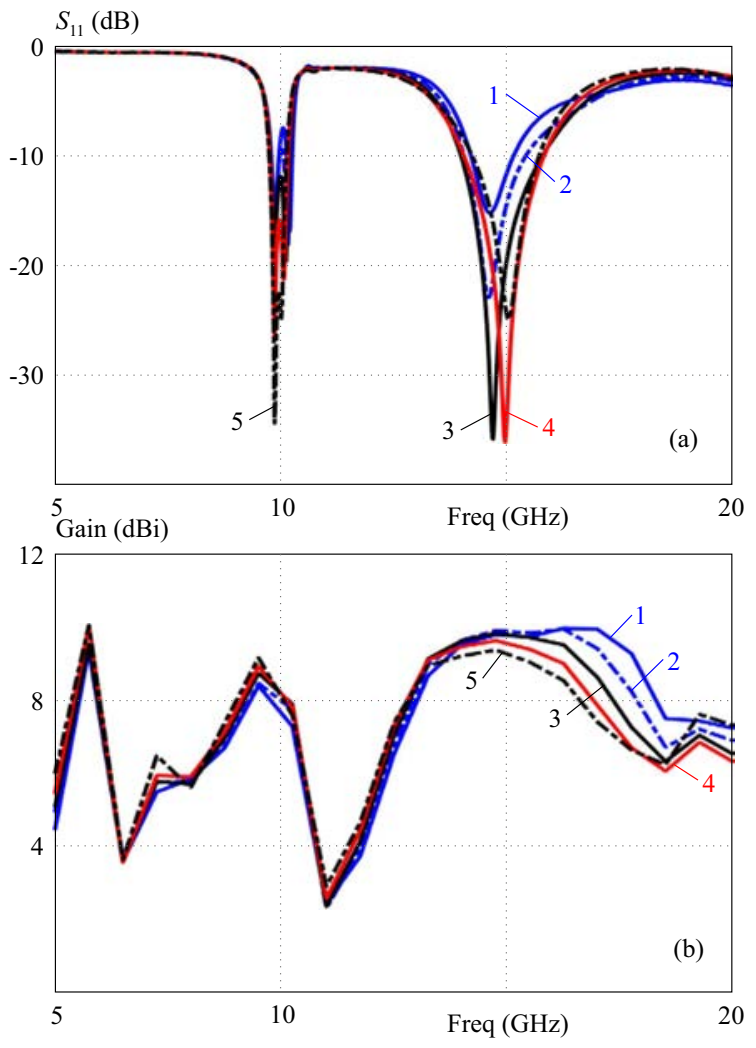

Fig. 14. Electric and magnetic fields on the ground plane in the near field at $10 \mathrm{GHz}$ : (a) $-E$-field, (b) $-H$-field
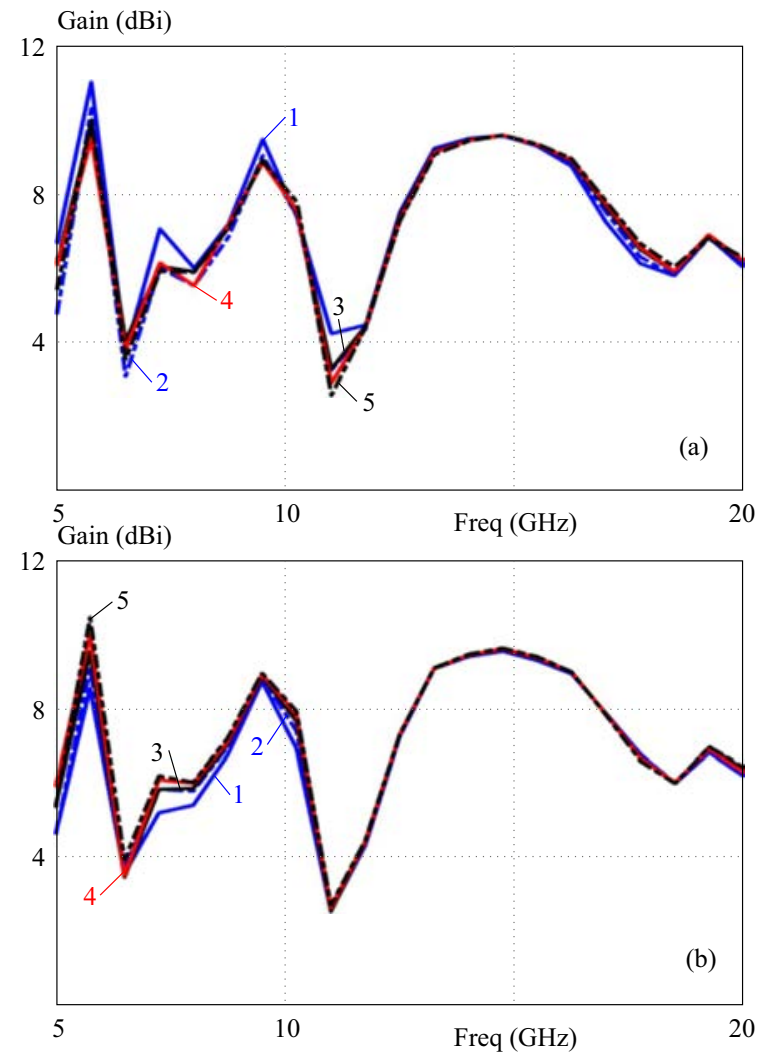

Fig. 15. Electric and magnetic fields on the ground plane in the near field at $15 \mathrm{GHz}$ : (a) $-E$-field, (b) $-H$-field

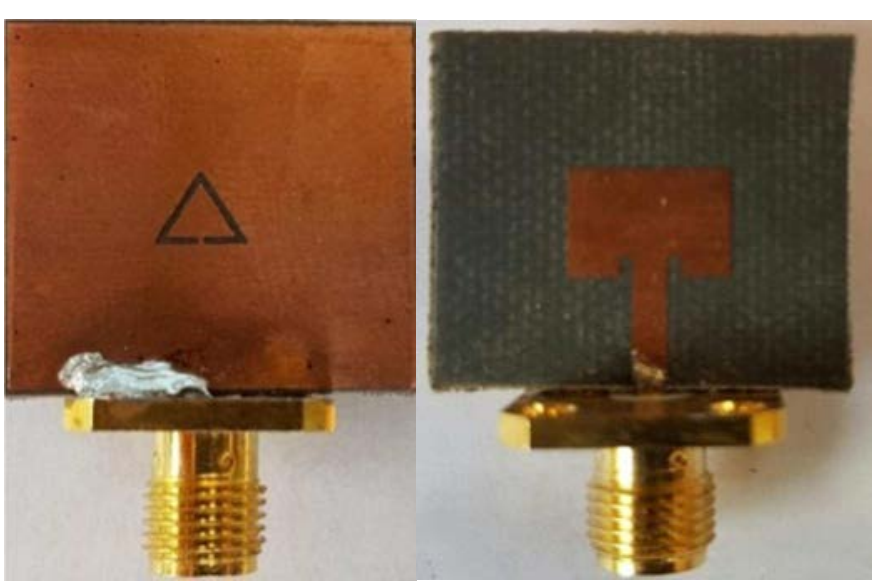

(a)

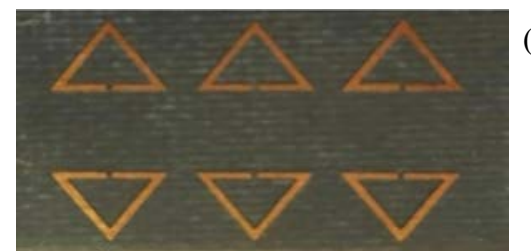

(b)

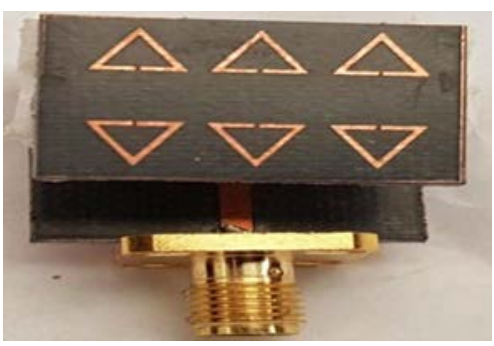

(c)

Fig. 16. Prototype of (a) - fabricated unloaded antenna, (b) - TSRR MTM superstrate, (c) - perspective view

Another two important parameters that can be manipulated to maximize the gain are the vertical and horizontal spacing $\left(S_{\mathrm{Y}}\right.$ and $S_{\mathrm{X}}$ ) between each two adjacent TSRR unit cells. Figures 15(a) and (b) show the variation of gain with change in $S_{\mathrm{X}}$ and $S_{\mathrm{Y}}$. Maximum gain is obtained for $S_{X}=1.2 \mathrm{~mm}$ and $S_{Y}=4.9 \mathrm{~mm}$.

Placing the MTM superstrate above the patch at a small height gives rise to a parasitic loading of the traditional patch antenna. Because of this parasitic loading, proximity coupling between the TSRR MTM superstrate and patch take place, consequently forming a two layer electromagnetically coupled system. This electromagnetic coupling between the patch and TSRR MTM superstrate produces an enrichment of the bandwidth of the composite system.

The proposed antenna gain improvement can be explained by means of the cavity effect that arises when the TSRR MTM superstrate placed at a convenient distance above the patch. As per Snells Law of refraction, the medium with low refractive index moves the electromagnetic waves afar from the main source and in the direction to the normal of this surface. This feature improves sig- 
$S_{11}(\mathrm{~dB})$

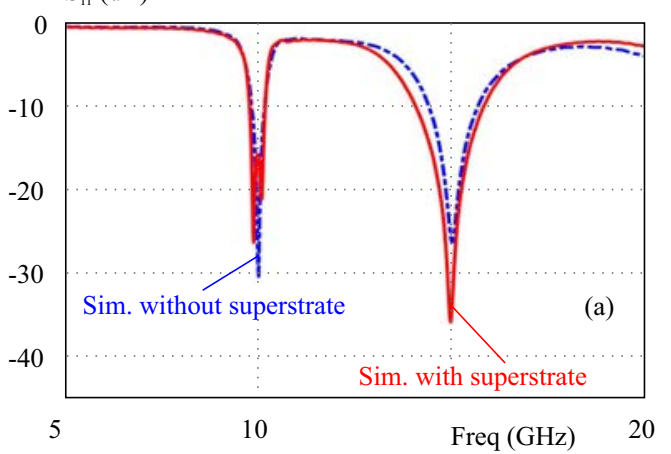

$S_{11}(\mathrm{~dB})$

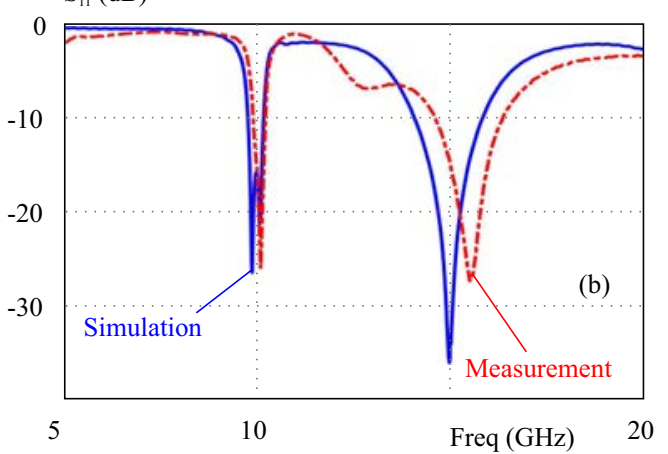

Fig. 17. S11 characteristics of the proposed antenna: (a) - with and without superstrate, (b) - measured and simulated with superstrate
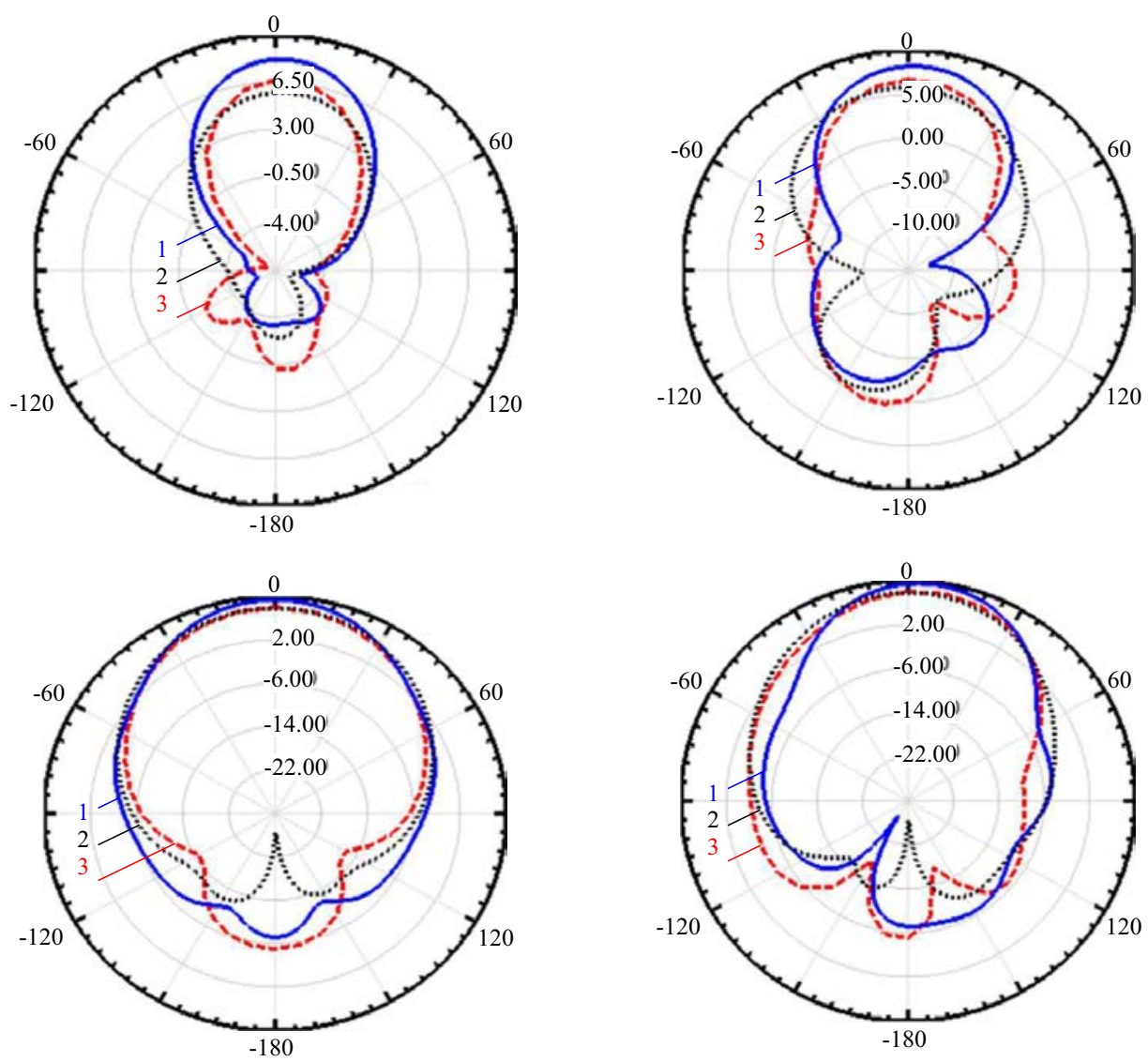

Fig. 18. Simulated and measured radiation patterns: (a) - E-plane at $10 \mathrm{GHz},(\mathrm{b})-H$-plane at $10 \mathrm{GHz},(\mathrm{c})-E$-plane at $15 \mathrm{GHz}$, (d) $-H$-plane at $15 \mathrm{GHz}$

nificantly the directivity of the proposed antenna. The MTM superstrate performs as a highly reflective surface, rendering the antenna highly directive. The presence of MTM superstrate also makes the field distribution of the antenna more homogeneous, thus improving overall gain of the proposed antenna.

\section{Fabricated superstrate antenna and results}

To demonstrate the validity of the design, EM simulated results of the proposed superstrate antenna are compared with actual measurements in this section. Testing of the antenna hardware was performed on the R\&S
ZVA 67 VNA (Vector Network Analyzer) at $10 \mathrm{MHz}$ to $67 \mathrm{GHz}$. Figures 16(a), (b), and (c) are photographs of the front and back views of the unloaded antenna, enlarged view of MTM superstrate, and perspective view of the fabricated MTM superstrate antenna, respectively. Figure 17(a) demonstrates the simulated S-parameters of the dual band patch antenna with and without MTM superstrate, while Fig. 17(b) shows the simulated and measured S-parameters of the proposed antenna under loading conditions.

It can be observed from Fig. 17(a) that the antenna without MTM superstrate resonates at 10 and $15 \mathrm{GHz}$ 


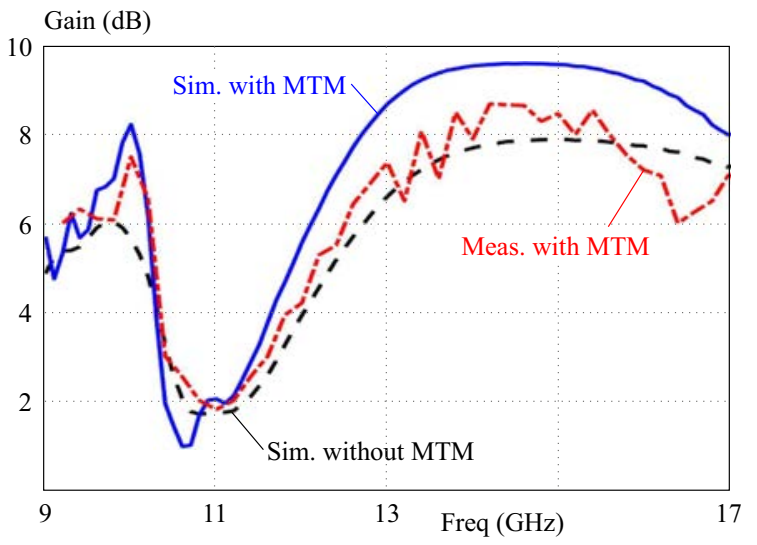

Fig. 19. Comparison between the measurement and EM simulation gains of the proposed antenna with and without MTM superstrate

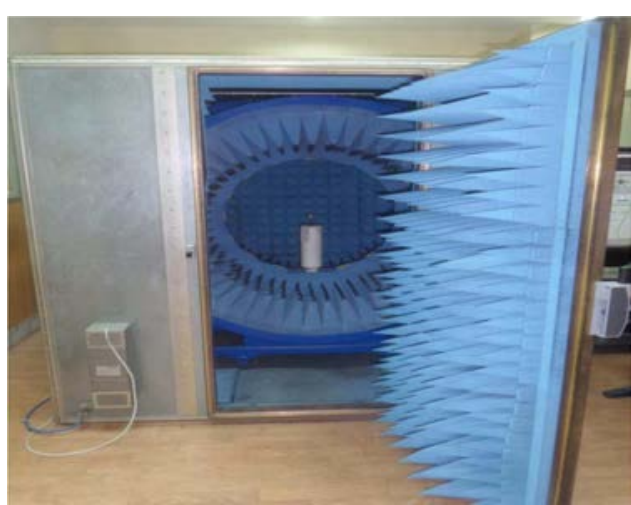

Fig. 21. Measurement setup in the Satimo StarLab

Table 2. Comparison among the results obtained in this work and recent papers

\begin{tabular}{lcccc}
\hline Ref. & $\begin{array}{c}\text { Dimensions } \\
\left(\mathrm{mm}^{2}\right)\end{array}$ & $\begin{array}{c}\text { BW } \\
(\mathrm{GHz})\end{array}$ & $\begin{array}{c}\text { Gain } \\
(\mathrm{dB})\end{array}$ & $\begin{array}{c}\text { Efficiency } \\
(\%)\end{array}$ \\
\hline$[27]$ & $30 \times 57$ & 0.685 & 11.9 & $\mathrm{NR}$ \\
{$[28]$} & $18 \times 21.28$ & 0.9 & 11.6 & $\mathrm{NR}$ \\
\hline & & 0.12 & 13 & \\
{$[29]$} & $27 \times 27$ & 0.135 & 5 & $\mathrm{NR}$ \\
& & $\mathrm{DB}$ & $\mathrm{DB}$ & \\
\hline$[30]$ & $13 \times 11$ & 0.164 & 7.53 & \\
\hline This & \multirow{3}{*}{$20 \times 20$} & 0.404 & 8.24 & 82 \\
Work & & 1.82 & 9.65 & 87 \\
& & $\mathrm{DB}$ & $\mathrm{DB}$ & $\mathrm{DB}$ \\
\hline
\end{tabular}

DB - dual band, NR - not reported

with a bandwidth of 0.307 and $1.3 \mathrm{GHz}$, respectively. In comparison, when the conventional antenna is covered with MTM TSRR superstrate the bandwidth reaches to 0.404 and $1.82 \mathrm{GHz}$ at the same resonant frequencies in sequence. From Fig. 17(b), it is observed that the fabricated antenna resonates at 10.05 and $15.4 \mathrm{GHz}$ with a bandwidth of 0.4 and $1.7 \mathrm{GHz}$, respectively, showing that both results are in good agreement between simu- (a)

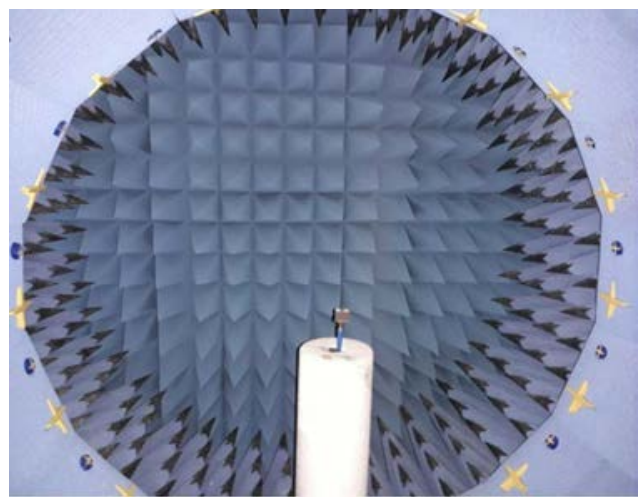

(b)

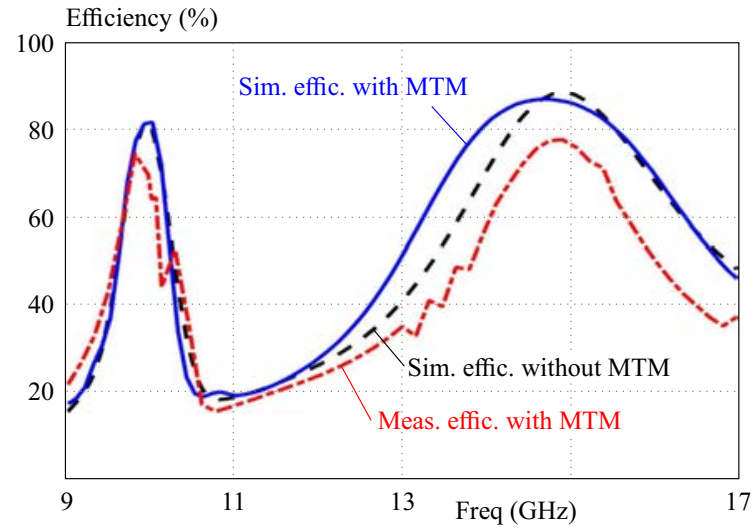

Fig. 20. Comparison between the measurement and EM simulation radiation efficiency of the proposed antenna with and without MTM superstrate

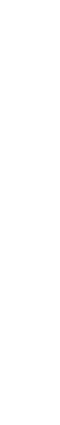

lation and measurement. However, there is a small difference between simulated and measured return loss of about $0.5 \%$ and $2.6 \%$, respectively due to a slight compromise in precision when fabricating the model.

A comparison between simulated and measured radiation patterns is shown in Fig. 18 for the proposed dual band MTM superstrate antenna. As shown in the figure, the simulated and measured $E$ - and $H$-planes of radiation pattern at the two frequencies are mostly directional. There was good agreement between the simulation and measurement results. Moreover, the radiation beam in both $\mathrm{E}$ plane and H-plane became more focused when the MTM superstrate was positioned on top of the patch. To verify the contention that antenna gain is improved as the beam becomes more focused, the gain versus frequency for the proposed antenna with and without MTM superstrate is plotted in Fig. 19. The simulated gain of the proposed antenna incorporated with an MTM superstrate improved from $5.78 \mathrm{~dB}$ to $8.24 \mathrm{~dB}$, and from $7.87 \mathrm{~dB}$ to $9.56 \mathrm{~dB}$ at 10 and $15 \mathrm{GHz}$, respectively.

The measured and simulated gains of the proposed antenna fell roughly within the antenna bandwidth, but with some fluctuation in the measured values. The reasons lies in the fact that CST software calculates the antenna gain as if there are no mismatch losses between antenna and SMA connector. Another reason, it might come 
from the misalignment in the placement of the MTM lens above the patch. It could be also due to fabrication tolerance or measurement errors. Regarding antenna efficiency shown in Fig. 20, it is important to note that the dielectric and the conductor losses increased because of the added MTM superstrate and, consequently, a slight degradation in antenna overall efficiency is to be expected. However, the directivity of the antenna increased significantly due to beam focusing of the radiated wave, and this more than offset the slight loss in radiation efficiency. Consequently, antenna gain was upgraded overall.

The antenna gain, efficiency, and radiation pattern characteristics were measured using the Satimo StarLab near-field antenna measurement setup ranging from $800 \mathrm{MHz}$ to $6 \mathrm{GHz}$, and from $6 \mathrm{GHz}$ to $18 \mathrm{GHz}$ as shown in Fig. 21. This system allows measurement of the antennas electric fields within the near-field region for computation of the corresponding far-field values of the antenna under test (AUT). The AUT was placed on the test board and positioned in the middle of a circular "arch" that contained 29 measuring probe antennas divided into 15 probes for the low frequency range, and 14 other probes for the high frequency range. These probes were placed at equal distance surrounding the circular surface. The $360^{\circ}$ horizontal rotation of the AUT, together with the probes, performed a full 3D scan of AUT and collected data for radiation patterns. The far-field data were then employed to compute the gain and efficiency of the antenna model.

Comparisons between the results achieved in this research with available latest literature are reported in Tab. 2. Most of the antennas have good results, while our proposed antenna uses a superstrate metamaterial to enhance gain and bandwidth simultaneously, and uses a novel method of exciting different characteristic modes to study the behavior of this proposed antenna.

\section{Conculsion}

In this paper, a MTM superstrate loaded on to a patch antenna is developed for $5 \mathrm{G}$ wireless communications. The MTM superstrate, with a total area of $2 \times 15 \mathrm{~mm}^{2}$, comprises a $3 \times 2$ triangular split ring resonator on a $1.575 \mathrm{~mm}$ thick Rogers substrate of 2.2 relative permittivity. The MTM superstrate is positioned $12.5 \mathrm{~mm}$ above the patch. The proposed composite structure enhances the antenna gain and operating bandwidth simultaneously. A double band characteristic of the antenna is utilized by incorporating a complementary triangular split ring resonator on the ground plane. Characteristic mode analysis shows this approach to be effective in the modeling and design of the proposed antenna. A comparison of the performance of the MTM superstrate-loaded antenna with that of the conventional unloaded control showed metamaterials to have good potential for improving antenna performance. A prototype of the proposed antenna was fabricated and good agreement between measurement and simulation results was achieved.

\section{REFERENCES}

[1] M. R. Bhalla and A. V. Bhalla, "Generations of Mobile Wireless Technology: A Survey", International Journal of Computer Applications vol. 5, no, 4,, pp. 26-32, 2010.

[2] S. Ohmori, Y. Yamao, and N. Nakajima, "The Future Generations of Mobile Communications Based on Broadband Access Technologies", IEEE Communication Magazine vol. 38, no, 12, pp. 134-142, 2010.

[3] M. M. M. Ali, O. Haraz, and S. Alshebeili, "Design of Dual-Band Printed Slot Antenna with Utilizing a Band Rejection Element for the 5G Wireless Applications", IEEE International Symposium on Antennas Propagation, Fajardo, Puerto Rico, 26 June - 1 July, pp. 1865-1866, 2016.

[4] S. F. Jilani and A. Alomainy, "Millimetre-wave T-Shaped MIMO Antenna with Defected Ground Structures for 5G Cellular Networks", IET Microwaves Antennas \& Propagation, vol. 12, no, 5,, pp. 672-677, 2018.

[5] A. Kumar, N. Gupta, and P. C. Gautam, "Gain Bandwidth Enhancement Techniques in Microstrip Patch Antennas - a review", International Journal of Computer Applications vol. 148, no, 7, pp. 9-14, 2016.

[6] V. G. Veselago, "The Electrodynamics of Substances with Simultaneously Negative Values of $\varepsilon$ and $\mu$ ", Soviet Physics vol. 10, no, 4,, pp. 509-514, 1968

[7] D. R. Smith, J. B. Pendry, and M. C. K. Wiltshire, "Metamaterials Negative Refractive Index", Science vol. 305, pp. 788-792, 2004.

[8] Y. Dong and T. Itoh, "Metamaterial-Based Antennas", IEEE Proceedings vol. 100, no, 7, pp. 2271-2285, 2012.

[9] P. D. Tung, P. H. Lam, and N. T. Q. Hoa, "A Miniaturization of Microstrip Antenna using Negative Permittivity Metamaterial Based on CSRR-Loaded Grounded for WLAN Applications", Journal of Science Technology, vol. 54, no, 6, pp. 689-697, 2016.

[10] A. B. Abdel-rahman and A. A. Ibrahim, "Metamaterial Enhances Microstrip Antenna Gain", Microwaves and RF vol. 55 , no, 7, pp. 46-50, 2016.

[11] E. K. I. Hamad, W. A. E. Ali, M. Z. M. Hamdallah, et al, "High Gain Triple Band Microstrip Antenna Based on Metamaterial Super Lens for Wireless Communication Applications", Int Conference on Innovative Trends in Computer Engineering (ITCE), Aswan, Egypt, 19-21 Feb, pp. 197-204, 2018.

[12] W. Wu, B. Yuan, B. Guan, and T. Xiang, "A Bandwidth Enhancement for Metamaterial Microstrip Antenna", Microwave Optical Technology Letter vol. 59, no, 12, May, pp. 3076-3082, 2017.

[13] S. Chaimool, K. L. Chung, and P. Akkaraekthalin, "Simultaneous Gain Bandwidths Enhancement of a Single-Feed Circularly Polarized Microstrip Patch Antenna Using a Metamaterial Reflective Surface", Progress in Electromagnetics Research B vol. 22, no, 1, pp. 23-37, 2010.

[14] K. Sun, S. Han, J. H. Choi, et al, "Miniaturized Active Metamaterial Resonant Antenna with Improved Radiation Performance Based on Negative-ResistanceEnhanced CRLH Transmission Lines", IEEE Wireless Propagation Letter vol. 17, no, 7, pp. 1162-1165, 2018.

[15] S. H. Zainud-deen, A. M. Mabrouk, and H. A. Malhat, "Terahertz Graphene Based Metamaterial Transmitarray", Wireless Personal Communications vol. 99, no, 1, pp. 1-14, 2018.

[16] M. I. Ibrahim, A. M. E. Safwat, and H. El-hennawy, "Single/Dual-Band CSRR-Loaded Differential-Fed Square Patch Antenna with Monopolar Radiation Pattern", $33^{\text {rd }}$ National Radio Science Conference (NRSC) Aswan, Egypt, 22-25 Feb, pp. 81-86, 2016.

17] D. Faktorova, P. Omelka, and K. Istenikova, "Antenna Parameters Enhancement by Using Artificial Magnetic Structure", Journal of Electrical Engineering vol. 61, no, 7, pp. 156-159, 2010. 
[18] D. A. Outerelo, A. V. Alejos, M. G. Sanchez, et al, "Microstrip Antenna for $5 \mathrm{G}$ broadband Communications: Overview of Design Issues", IEEE International Symposium on Antennas Propagation \& USNC/URSI National Radio Science Meeting, Vancouver, BC, Canada, 19-24 July, pp. 2443-2444, 2015.

[19] D. M. Pozar and D. H. Schaubert, "Microstrip Antenna, the Analysis and Design of Microscript Antenna and Array", New York, USA, 1995.

[20] A. Bage and S. Das, "Studies of some Non-Conventional Split Ring Complementary Split Ring Resonators for Waveguide Band Stop \& Band Pass Filter Application", International Conference on Microwave Photonics (ICMAP), Dhanbad, India, 13-15 Dec, pp. 1-5, 2013.

[21] R. W. Ziolkowski, "Design, Fabrication and Testing of Double Negative Metamaterials", IEEE Transactions on Antennas Propagation vol. 51, no, 7, pp. 1516-1529, 2003.

[22] F. Falcone, T. Lopetegi, and M. A. G. Laso, "Babinet Principle Applied to the Design of Metasurfaces Metamaterials", Physical Review Letters vol. 93, no, 19, pp. 1-4, 2004.

[23] R. J. Garbacz, "Modal Expansions for Resonance Scattering Phenomena", IEEE Proceedings vol. 53, no, 8, pp. 856-864, 1965.

[24] R. F. Harrington and J. R. Mautz, "Theory of characteristic Modes for Conducting Bodies", IEEE Transactions on Antennas Propagation vol. 19, no, 5, pp. 622-628, 1971.

[25] R. F. Harrington and J. R. Mautz, "Computation of Characteristic Modes for Conducting Bodies", IEEE Transactions on Antennas Propagation vol. 19, no, 5, pp. 629-639, 1971.

[26] Y. Chen and C. Wang, "Characteristic Modes Theory Applications in Antenna Engineering", Hoboken NJ, USA: John Wiley \& Sons, 2015.

[27] C. Arora, S. S. Pattnaik, and R. N. Baral, "Metamaterial Inspired DNG Superstrate for Performance Improvement of Microstrip Patch Antenna Array", International Journal of Microwave Wireless Technologies vol. 10, no. 3, pp. 318-327, 2018.

[28] A. A. Abdelrehim and H. Ghafouri-shiraz, "Performance Improvement of Patch Antenna Using Circular Split Ring Resonators Thin Wires Employing Metamaterials Lens", Progress Electromagnetics Research vol. 69, pp. 137-155, 2016.

[29] B. Thakur and A. Kunte, "Compact Dual-Band Patch Antenna Using Triangular Complimentary Split Ring Resonators for WiMax/WLAN", International Conference on Communication information Computing Technology (ICCICT) Mumbai, India, 2-3 Feb, pp. 1-4, 2018.

[30] B.Tütüncü and H. Torpi, Omega-Shaped Metamaterial Lens Design for Microstrip Patch Antenna Performance Optimization at
$12 \mathrm{GHz}$, International Conference on Electrical Electronics Engineering (ELECO), Bursa, Turkey, 30 Nov - 2 Dec, pp. 987-990, 2017 .

Received 20 December 2018 Revised 20 March 2019

Ehab K. I. Hamad earned his bachelor and master degrees in Electrical Engineering from Assiut University, Egypt in 1994 and 1999, respectively. He received his $\mathrm{PhD}$ degree in Electrical Engineering from University of Magdeburg, Germany in 2006. From 1996 to 2001 he was a Teaching/Research assistant at Aswan Faculty of Engineering, South Valley University. From July 2001 to December 2006, he was a Research Assistant at the Chair of Microwave and Communication Engineering, Otto-von-Guericke University Magdeburg, Magdeburg, Germany. From July 2010 to April 2011; he joined the School of Computing and Engineering, University of Huddersfield, Huddersfield, UK as a Post-doctoral Research Assistant. He is currently an Associate Professor for microwave antennas at the Department of Electrical Engineering, Faculty of Engineering, Aswan University, Aswan, Egypt. He has authored and co-authored over 45 technical peer reviewed papers in international journals and conference proceedings and he received 1 best paper award. His current research interests include: Antenna design, Microstrip antennas, MIMO antennas, mm-Wave antennas, Multiband/wideband small antennas for 4G/5G, UWB, RFID, metamaterials, metasurfaces, and RF energy harvesting. He is working now on designing microstrip antennas for $5 \mathrm{G}$ wireless communications using characteristics mode analysis.

Ahmed Abdelaziz received the BE degree in Electronic \& Communication Engineering from Arab Academy for Science, Technology and Maritime Transport, Egypt in 2014. He earned his Master Degree in Electrical Engineering from the Faculty of Engineering, Aswan University in February 2019. Eng. Ahmed is working now as Teaching/Research Assistant at Luxor Higher Institute of Engineering \& Technology, Luxor, Egypt. His current research interests include the antenna design, Microstrip antennas, metamaterials, characteristic mode theory, and 5G. 